\title{
Regulation of the adaptation to ER stress by KLF4 facilitates melanoma cell metastasis via upregulating NUCB2 expression
}

Dongmei Zhang ${ }^{1,3+}$, Jingrong $\mathrm{Lin}^{4 \dagger}$, Yulin Chao ${ }^{1+}$, Lu Zhang ${ }^{2}$, Lei $\mathrm{Jin}^{1}, \mathrm{Na} \mathrm{Li}^{3}$, Ruiping $\mathrm{He}^{1}$, Binbin $\mathrm{Ma}^{2}$, Wenzhi Zhao ${ }^{2^{*}}$ and Chuanchun Han ${ }^{1 *}$

\begin{abstract}
Background: Adaptation to ER stress has been indicated to play an important role in resistance to therapy in human melanoma. However, the relationship between adaptation to ER stress and cell metastasis in human melanoma remains unclear.

Methods: The relationship of adaptation to ER stress and cell metastasis was investigated using transwell and mouse metastasis assays. The potential molecular mechanism of KLF4 in regulating the adaptation to ER stress and cell metastasis was investigated using RNA sequencing analysis, q-RT-PCR and western blot assays. The transcriptional regulation of nucleobindin 2 (NUCB2) by KLF4 was identified using bioinformatic analysis, luciferase assay, and chromatin immunoprecipitation (ChIP). The clinical significance of KLF4 and NUCB2 was based on human tissue microarray (TMA) analysis.

Results: Here, we demonstrated that KLF4 was induced by ER stress in melanoma cells, and increased KLF4 inhibited cell apoptosis and promoted cell metastasis. Further mechanistic studies revealed that KLF4 directly bound to the promoter of NUCB2, facilitating its transcription. Additionally, an increase in KLF4 promoted melanoma ER stress resistance, tumour growth and cell metastasis by regulating NCUB2 expression in vitro and in vivo. Elevated KLF4 was found in human melanoma tissues, which was associated with NUCB2 expression.
\end{abstract}

Conclusion: Our data revealed that the promotion of ER stress resistance via the KLF4-NUCB2 axis is essential for melanoma cell metastasis, and KLF4 may be a promising specific target for melanoma therapy.

Keywords: Melanoma, ER stress, Apoptosis, KLF4, Metastasis

\section{Background}

Melanoma is the most aggressive skin cancer and is associated with a high mortality rate [1]. In the past, multiple strategies have been used for melanoma treatment. For primary melanoma, surgical resection was the best option and the patients have a good post-treatment

\footnotetext{
*Correspondence: drzwz@163.com; hanchuanchun@163.com

†Dongmei Zhang, Jingrong Lin and Yulin Chao contributed equally to this work.

${ }^{2}$ Department of Orthopedics, Second Affiliated Hospital, Dalian Medical University, Dalian 116044, China

${ }^{1}$ Institute of Cancer Stem Cell, Dalian Medical University, Dalian 116044,

China

Full list of author information is available at the end of the article
}

prognosis. For metastatic melanoma, only a few options were clinically available for treating the disease such as targeting BRAF and MEK using small molecule inhibitors, immunotherapeutic antibodies against the immune checkpoints T-lymphocyte-associated antigen 4 (CTLA-4) and programmed cell-death protein 1 (PD-1) and the modified oncolytic herpes virus talimogene laharparepvec (T-VEC) and the 5-year survival rate of patients has been improved to some extent [2-14]. However, similar to other cancers, distant metastasis is still a major obstacle to the treatment of melanoma. Thus, understanding the potential molecular mechanisms of tumour metastasis is 
important for improving the overall prognosis of patients with melanoma.

Metastasis is a multi-step process releasing tumour cells from a primary lesion to a disparate organ or organs within the body. Tumour cells change their characteristics throughout the process, which enables them to proliferate and migrate, invading surrounding tissues [15]. When tumours metastasise, the cells undergone diverse microenvironments such as hypoxia, nutrient starvation, leading to endoplasmic reticulum (ER) stress [16].

Previous studies have indicated that melanoma largely adapts to ER stress depending on a series of potential molecular mechanisms including upregulation of the antiapoptotic Bcl-2 family protein $\mathrm{Mcl}-1$ by miR-149* or activation of autophagy by RIPK1 [17-19]. Our recent study indicated that the increase of cancer stem cells by HOXB9 inhibited ER stress-induced apoptosis in melanoma cells [20]. Although the adaptation to ER stress has been reported to play a role in the resistance of melanoma cells to various therapeutic agents, the role of adaptation to ER stress in melanoma metastasis is still unclear.

Here, we found that KLF4, a zinc finger-type transcription factor, was induced by ER stress, leading to the inhibition of cell apoptosis and the promotion of cell metastasis in melanoma. Further mechanistic studies revealed that KLF4 directly bound to the promoter of NUCB2 and facilitated its transcription. In addition, KLF4 promoted melanoma ER stress resistance, tumour growth and cell metastasis by regulating NCUB2 expression in vitro and in vivo. Elevated KLF4 was found in human melanoma tissues, which was associated with NUCB2 upregulation. Therefore, our finding suggests that the KLF4-NUCB2 pathway may be an important apparatus in melanoma metastasis under ER stress.

\section{Methods}

\section{Cell culture and reagents}

Human melanoma cell lines Me1007, Mel-RM, A375, Mel-CV, and SK-Mel-28 were obtained as previously described [21]. Studies on a panel of melanoma cell lines revealed that ER stress did not induced significantly apoptosis in Mel-RM, A375, Mel-CV, SK-Mel-28 but Me1007. Me1007 was reported to be a ER stress non-resistant melanoma cell line [22]. These cells were cultured in DMEM containing 10\% FBS (ExCell Bio, Lot: FSP500) and $0.1 \%$ Savelt $^{\mathrm{Tx}}$ (Hanbio Co. LTD., 1:1000). The following antibodies were used in this study: antibodies against GAPDH (Santa Cruz Biotechnology, Dallas, TX, USA; SC-25778, 1:1000); PARP (Santa Cruz Biotechnology, SC-8007, 1:1000); KLF4 (Santa Cruz Biotechnology, SC-20691, 1:10 for ChIP); KLF4 (Cell Signaling Technology, \#12173S, 1:500); NUCB2 (Abcam, ab229683, 1:300); KLF8 (Abcam, ab168527, 1:300); KLF5 (Proteintech, 21,017-1-AP 1:500); KLF6 (Proteintech, 14,716-1-AP 1:500); GRP78 (Santa Cruz Biotechnology, SC-13968,1:1000). Tunicamycin (TM, Lot:T7765) and thapsigargin (TG, Lot:T9033) were purchased from Sigma Chemical Co. They was dissolved in DMSO and made up in stock solutions of $3 \mathrm{mmol} / \mathrm{L}$ for tunicamycin and $1 \mathrm{mmol} / \mathrm{L}$ for thapsigargin. The cells were treated with $3 \mu \mathrm{mol} / \mathrm{L} \mathrm{TM}$ or $1 \mu \mathrm{mol} / \mathrm{L} \mathrm{TG}$ as the indicated times.

\section{Plasmids and transfection}

KLF4 and NUCB2 were constructed into pCDNA3.0-Flag vector. The lentiviral expression vector for KLF4 was constructed by inserting full-length cDNA into a $\mathrm{pCDH}$ vector. $5 \mu \mathrm{g}$ plasmids were transfected into melanoma cells $\left(1 \times 10^{6}\right)$ using Lipofectamine 3000 (Invitrogen, Carlsbad, CA, USA) according to the Lipofectamine ${ }^{\mathrm{Tx}} 3000 \mathrm{Re}-$ agent Protocol; The empty vectors were used as the negative control. To generate lentivirus expressing KLF4, HEK $293 \mathrm{~T}$ cells grown on a $6 \mathrm{~cm}$ dish were transfected with $2 \mu \mathrm{g}$ pCDH-KLF4 or control vector (pCDH), $1.5 \mu \mathrm{g}$ psPax2, and $0.5 \mu \mathrm{g}$ pMD2G. Twenty-four hour after the transfection, cells were cultured with DMEM containing $10 \%$ FBS for an additional $24 \mathrm{~h}$. The culture medium containing lentiviral particles was centrifuged at $1000 \mathrm{~g}$ for $5 \mathrm{~min}$. Viral particles collected in the supernatant were used for infection. In order to establish the stable cell line, the puromycin was used as a selection marker for the infected cells. The expression efficiency was evaluated by western blot analysis.

\section{RNA interference and KLF4 knockout cell}

RNA interference was performed as previously described $[20,23]$. The sequences targeting NUCB2-1 were: 5CCACAGATTTAGATATGCTAA-3 and NUCB2-2 5-G CGTGAATATCATCAGGTCAT-3. KLF4-1, 5-ATCGGT CATCAGCGTCAGCAA-3. KLF4-2 5-AAGTCATCTTG TGAGTGGATAA-3.

KLF4 knockout was achieved by CRISPR/Cas9. sgRNA design and cloning were performed according to the Feng Zhang lab general cloning protocols. KLF4 sgRNAs oligos were designed based on the target site sequence (20 bp) and were flanked on the 3' end by a 3 bp NGG PAM sequence. Using the Cas9 target design tools (http://www.genome-engineering.org), we designed two sgRNAs for each target: KLF4 sg1 UP:5-CACCCGCCG GGCCAGACGCGAACG-3. DN:5-AAACCGTTCGCG TCTGGCCCGGCG-3; Sg2 UP:5-CACCGTCTTTCTCC ACGTTCGCGTC-3 DN:5-AAACGACGCGAACGTGG AGAAAGAC-3. The sgRNAs were cloned into the lentiCRISPRv2 vector (Addgene). For lentivirus production, cloned lentiCRISPRv2 plasmids were co-transfected into HEK293T cells with the packaging plasmids pVSVg (AddGene 8454) and psPAX2 (AddGene 12,260). The 
lentivirus was harvested, and Mel-RM cells were infected with two sgRNA mixtures for KLF4. Forty-eight hours after infection, the cells were placed under puromycin selection for 2 weeks, and the single-cell-derived clones were picked, expanded and knockout of KLF4 was verified by western blot analysis.

\section{Tissue microarrays and immunohistochemistry}

Melanoma tissue microarrays were purchased from Alenabio (Xi'an, China), and they contained a total of 30 melanoma tissues and normal tissues. The immunohistochemistry was performed as previously described [24]. The characteristics of the patients and their tumours were collected through the review of medical records and pathologic reports. Informed consent with approval of the ethics committee of Taizhou Hospital of Zhejiang Province was obtained. All of the methods in this study were in accordance with the approved guidelines, and all of the experimental protocols were approved by the ethics committee of Taizhou Hospital of Zhejiang Province.

Sections were stained with Masson's trichrome and H\&E (haematoxylin and eosin) for histopathological examination. For immunohistochemistry, sections were subjected to antigen retrieval using microwave heating at $95{ }^{\circ} \mathrm{C}$ in citrate buffer $(\mathrm{pH}=6.0$, for $\mathrm{KLF} 4$ and NUCB2). The indicated antibodies specific for KLF4 (1:200) and NUCB2 (1:100) were diluted according to the manufacturer's instructions. The degrees of immunostaining were reviewed and scored by two independent observers. The proportion of the stained cells and the extent of the staining were used as criteria of evaluation. For each case, at least 1000 tumor cells were analyzed. For each sample, the proportion of KLF4 and NUCB2-expressing cells varied from 0 to $100 \%$, and the intensity of staining varied from weak to strong. One score was given according to the percentage of positive cells as: $<5 \%$ of the cells: 1 point; $6-35 \%$ of the cells: 2 point; $36-70 \%$ of the cells: 3 point; $>70 \%$ of the cells: 4 point. Another score was given according to the intensity of staining as: negative staining: 1 point; weak staining (light yellow): 2 point; moderate staining (yellowish brown): 3 point; and strong staining (brown): 4 point. A final score was then calculated by multiple the above two scores. If the final score was equal or bigger than four, the protein expression in the tumor was considered high; otherwise, the protein expression in the tumor was considered low. The clinical information of patients with melanoma was provided in the Additional file 1.

\section{ChIP assay}

The ChIP assay was performed as previously described [25].
Quantitative real-time polymerase chain reaction assay (q-RT-PCR) Total RNA was isolated using Trizol (Invitrogen). One microgram of total RNA was used to synthesize cDNA using the PrimeScript ${ }^{\text {tw }}$ RT reagent kit (Takara, RR047A) according to the manufacturer's instructions. The primers were as follows: NUCB2 up: 5CCTGTGGAAAGTGCGAAGATAG -3, dn: 5- GCCT CCCACTCTTTATTTCCTC -3; and ACTIN up: 5-GACC TGACTGACTACCTCATGAAGAT-3, dn: 5-GTCACAC TTCATGATGGAGTTGAAGG-3. KLF4 up: 5- ACCT ACACAAAGAGTTCCCATC-3; dn: 5-TGTGTTTACGG TAGTGCCTG-3. KLF5 up: 5- GAAGGAGTAACCCC GATTTGG-3; dn:5- CTTCCCAGGTACACTTGTATG G-3; KLF6 up:5- CTTTAACGGCTGCAGGAAAG-3, dn 5- GGAAGTGCCTGGTTAACTCATC-3; KLF8 up: 5CTCACCGCAGAATCCATACAG-3, dn 5- GCACCGAA AAGGCTTGATG-3.

\section{Promoter reporters and dual-luciferase assay}

The promoter of NUCB2 and the matching mutant were constructed into the pGL3-basic vector. The luciferase activity was measured in a $1.5-\mathrm{ml}$ Eppendorf tube with a Promega Dual-Luciferases Reporter Assay kit (Promega E1980) according to the manufacturer's protocols after transfection. Relative Renilla luciferase activity was normalized to firefly luciferase activity. The assay was performed as previously described [26, 27].

\section{Cell migration assay}

The cell migration assay was performed in a 24-well transwell plate with 8-mm polyethylene terephthalate membrane filters (Corning) separating the lower and upper culture chambers. In brief, melanoma cells were treated as indicated and plated in the upper chamber at $1 \times 10^{3}$ cells per well in serum-free DMEM medium. The bottom chamber contained DMEM with 10\% FBS. Cells were allowed to migrate for $24 \mathrm{~h}$ in a humidified chamber at $37{ }^{\circ} \mathrm{C}$ with $5 \% \mathrm{CO} 2$. After the incubation period, the filter was removed and non-migrant cells on the upper side of the filter were detached using a cotton swab. Filters were fixed with $4 \%$ formaldehyde for $15 \mathrm{~min}$, and cells located in the lower filter were stained with $0.1 \%$ crystal violet for 20 min and photographed.

Cells were counted in four randomly selected fields. Cell counts are expressed as the average number of cells per field of view. Three independent experiments were performed.

\section{Tumour growth and metastasis assay}

Animal studies were conducted in accordance with the National Institute of Health Guide for the Care and Use of Laboratory Animals with the approval of the Animal Research Committee of Dalian Medical University. Male nude mice (4-6 weeks of age, $18-20 \mathrm{~g}$ ) were obtained 
from the SPF Laboratory Animal Center of Dalian Medical University (Dalian, China) and were randomly divided into indicated groups. The mice $(n=6)$ in the groups were subcutaneously injected with the indicated cells or the injection was administered through the lateral tail vein. After 12 days, the tumour size was measured every 3 days by Vernier callipers and converted to TV according to the following formula: TV $\left(\mathrm{mm}^{3}\right)$ $=\left(\mathrm{axb}^{2}\right) / 2$, where $\mathrm{a}$ and $\mathrm{b}$ are the largest and smallest diameters, respectively. All animals were killed 4 weeks after injection, and the transplanted tumours were removed, weighed and fixed for further study. The weight of the lung and metastatic nodules were measured in the mice that were injected through the lateral tail vein. Lung was fixed with $4 \%$ formalin, and embedded in paraffin blocks. Sections of lung were stained with hematoxylin and eosin and photographed. The metastatic nodules were counted.

\section{Caspase- 3 activity assay and cell viability assay}

Caspase-3 activity was analysed using the Caspase-3 Activity Assay Kit (Roche) according to the manufacturer's instructions. Briefly, the cell or tissue lysate was incubated with $100 \mu \mathrm{L}$ of caspase- 3 reagent at $37{ }^{\circ} \mathrm{C}$ for $1-2 \mathrm{~h}$, and then the fluorescence intensity (at 370-425 $\mathrm{nm}$ excitation and 490-530 $\mathrm{nm}$ emission wavelengths) was measured using a Spectra MAX M5 spectrophotometer (Molecular Devices).

The cells were plated in 96-well plates at a density of 1000 cells in $200 \mu \mathrm{l}$ of medium per well $24 \mathrm{~h}$ before the experiment. The cells were treated with TM as indicated in the figures, and the cell viability was determined using the CCK- 8 kit (Cell Counting Kit-8).

\section{Statistics and data analyses}

The data are expressed as the mean $\pm \mathrm{SD}$, and the statistical evaluation was performed using one-way analysis of variance (ANOVA). Values of $p<0.05$ were considered statistically significant.

\section{Results}

\section{ER stress-resistant melanoma cells possess a high} metastatic ability

To investigate the relationship between adaptation to ER stress and cell metastasis, we first compared the migratory capabilities of ER stress-sensitive melanoma cell Me1007 and ER stress-resistant melanoma cells Mel-CV, SK-Mel-28, A375 and Mel-RM. The ER stress-resistance phenotype of these melanoma cells was confirmed by the results of the CCK- 8 assay (Additional file 2: Figure S1). We found that ER stress-resistant cells possessed a higher migratory capability than the ER stress-sensitive melanoma cell Me1007 (Fig. 1a and b). Subsequently, Me1007, Mel-RM, and A375 cells were treated with $3 \mu \mathrm{M}$ tunicamycin (TM), which induced ER stress via the inhibition of glycosylation. The migratory abilities were examined using a transwell assay. As shown in Fig. 1c and d, ER stress enhanced the cell migration in resistant cells; however, migration was inhibited in Me1007 cells indicating that the adaptation to ER stress favoured cell migration in melanoma cells. To further confirm this finding, GFP-labelled MelRM, A375 and Me1007 cells $\left(5 \times 10^{4}\right)$ were intravenously injected into nude mice who were subjected to bioluminescent imaging at 4 weeks after injection. The ER stress-resistant cells, Mel-RM and A375, exhibited a significant increase in lung metastatic abilities at approximately 4 weeks (Fig. 1e). Consistently, histological analyses indicated a remarkable increase in the number of metastatic lesions produced by Mel-RM and A375 cells compared with that produced by Me1007 cells (Fig. 1f-h).

\section{KLF4 is increased in melanoma cells under ER stress treatment}

To illuminate the mechanism underlying the regulation of ER stress resistance and cell metastasis, Mel-RM cells were treated with $3 \mu \mathrm{M}$ TM for the indicated times, and then mRNA expression profiles were obtained by mRNA microarray analysis. The results revealed that more than 2100 upregulated and 2500 downregulated genes $(\mathrm{FC}>2)$ were obtained in Mel-RM cells that were treated with $3 \mu \mathrm{M}$ TM compared with that of control cells (Fig. 2a and $\mathrm{c}$ and Additional file 3: Table S1). Among the altered genes, we found that the KLF family genes KLF4, KLF5, KLF6 and KLF8 were changed in response to ER stress, and KLF4 was markedly upregulated under ER stress (Fig. 2b and d), which was confirmed by q-RT-PCR and western blot (Fig. 2e and f). To determine which gene may be involved in regulating ER stress resistance and cell metastasis, the expression levels of these genes were analysed in the ER stress non-resistant cell line Me1007 after $3 \mu \mathrm{M}$ TM treatment. We found that compared with ER stress-resistant cells, the induction of KLF4 by ER stress disappeared in Me1007 cells, and the basic expression level of KLF4 was downregulated in Me1007 cells (Fig. 2g-i). However, the alteration of KLF5, KLF6 and KLF8 by ER stress were similar with the ER stress resistant cells. To further confirm this finding, the expression levels of KLF4 were first assessed in A375 and SK-Mel 28 cells using q-RT-PCR and western blot. Consistently, the protein and mRNA levels of KLF4 were elevated under $3 \mu \mathrm{M}$ TM treatment (Fig. 2j-m). Then, we used $1 \mu \mathrm{M}$ thapsigargin (TG), a $\mathrm{Ca}^{2+}$-ATPase inhibitor, to induce ER stress and the protein and mRNA levels of KLF4 were analysed 
a

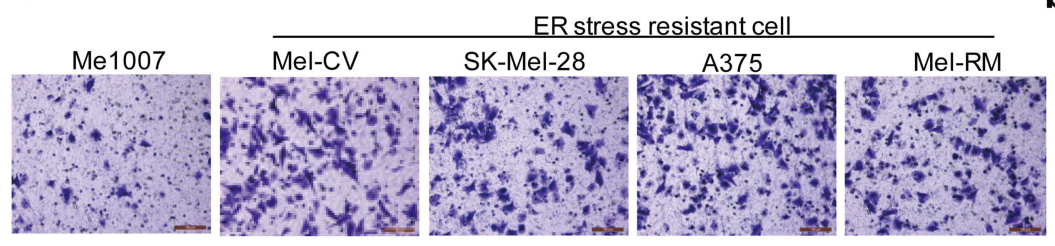

C

d

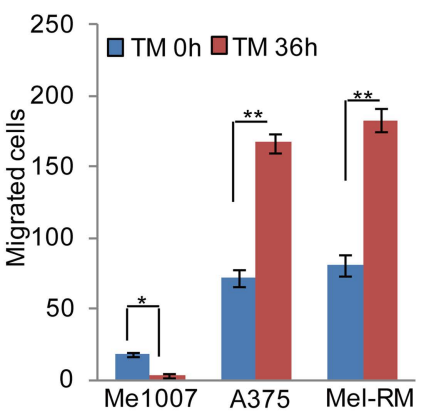

b

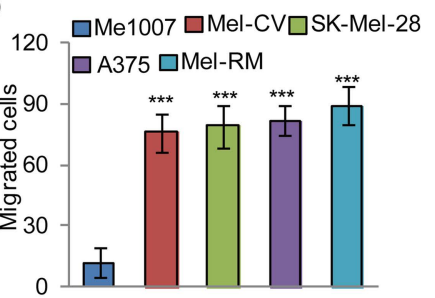

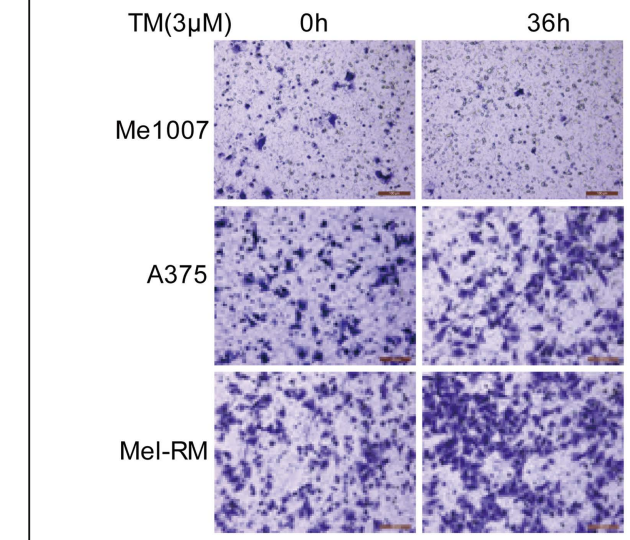

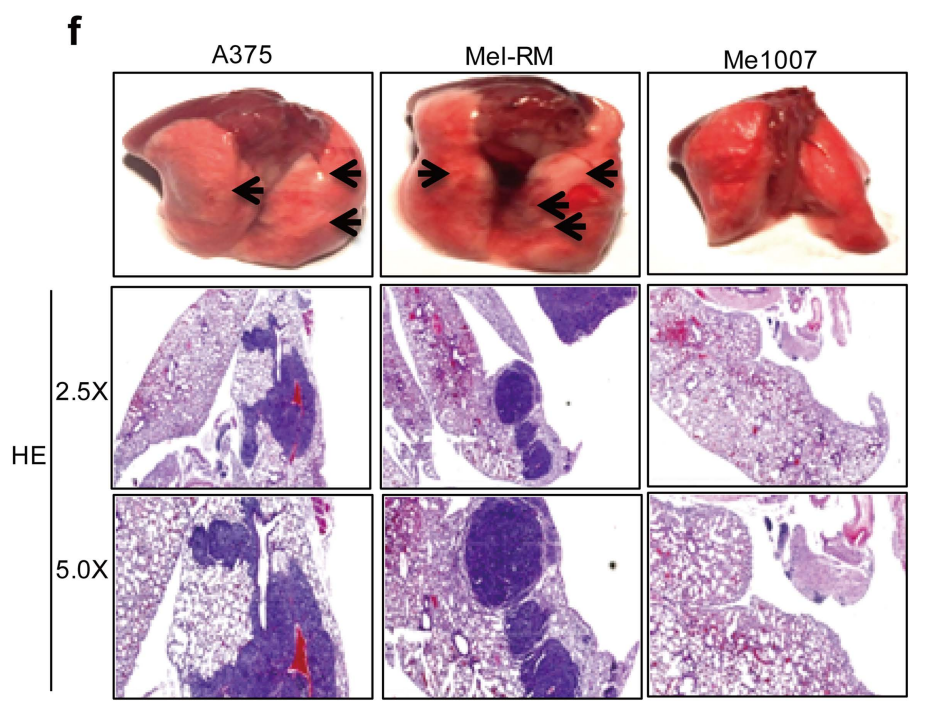

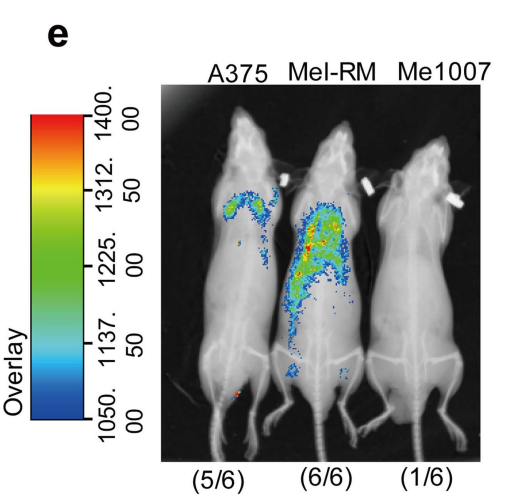

g
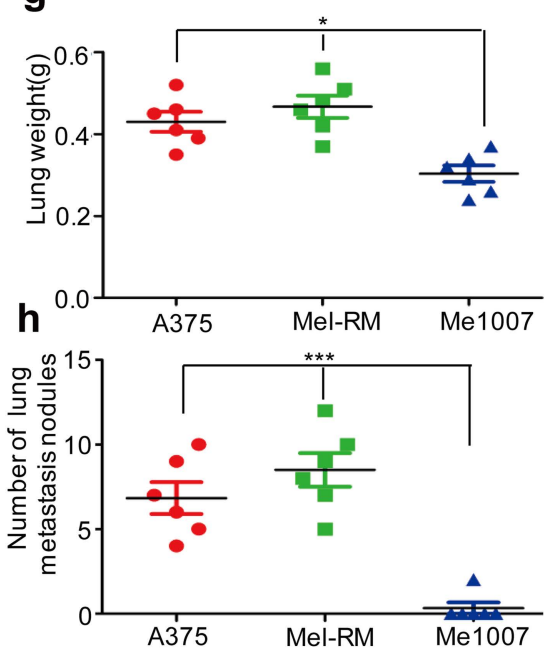

Fig. 1 ER stress-resistant cells exhibited more migratory phenotype. a-b The migration abilities of the melanoma cells were detected by a transwell assay. The data represent the means \pm SD of three independent experiments; ${ }^{* * *} p<0.001$ vs. control. c-d Me1007, A375 and Mel-RM cells were treated with $3 \mu \mathrm{M}$ TM as indicated. Cell migration was analysed by a transwell assay. The data represent the means \pm SD of three independent experiments; ${ }^{*} p<0.05,{ }^{* *} p<0.01$ vs. control. e GFP-labelled Mel-RM, A375 and Me1007 cells $\left(5 \times 10^{4}\right)$ were injected intravenously into nude mice $(n=6$ in one group). After 4 weeks, the mice were subjected to bioluminescent imaging. $\mathbf{f}$-h Representative images of the lung and HE pictures are shown $(\mathbf{f})$, the weight and metastasis nodule in each group were calculated $(\mathbf{g}-\mathbf{h}) ;{ }^{*} p<0.05,{ }^{* *} p<0.001$ vs. control

using western blot and q-RT-PCR. Similar with $3 \mu \mathrm{M}$ TM treatment, KLF4 was significantly increased in response to ER stress induced by $1 \mu \mathrm{M}$ TG (Additional file 4: Figure S2a and b). Thus, these data implied that KLF4 was a ER stress-induced gene and may contribute ER stress resistance of melanoma.
Increased KLF4 inhibits cell apoptosis and facilitates cell metastasis under ER stress

Given that KLF4 enhanced melanoma adaptation to ER stress, we first knocked down KLF4,KLF5 and KLF8 expression using shRNAs in Mel-RM and A375 cells. Then, these cells were treated with $3 \mu \mathrm{M}$ TM, and cell 


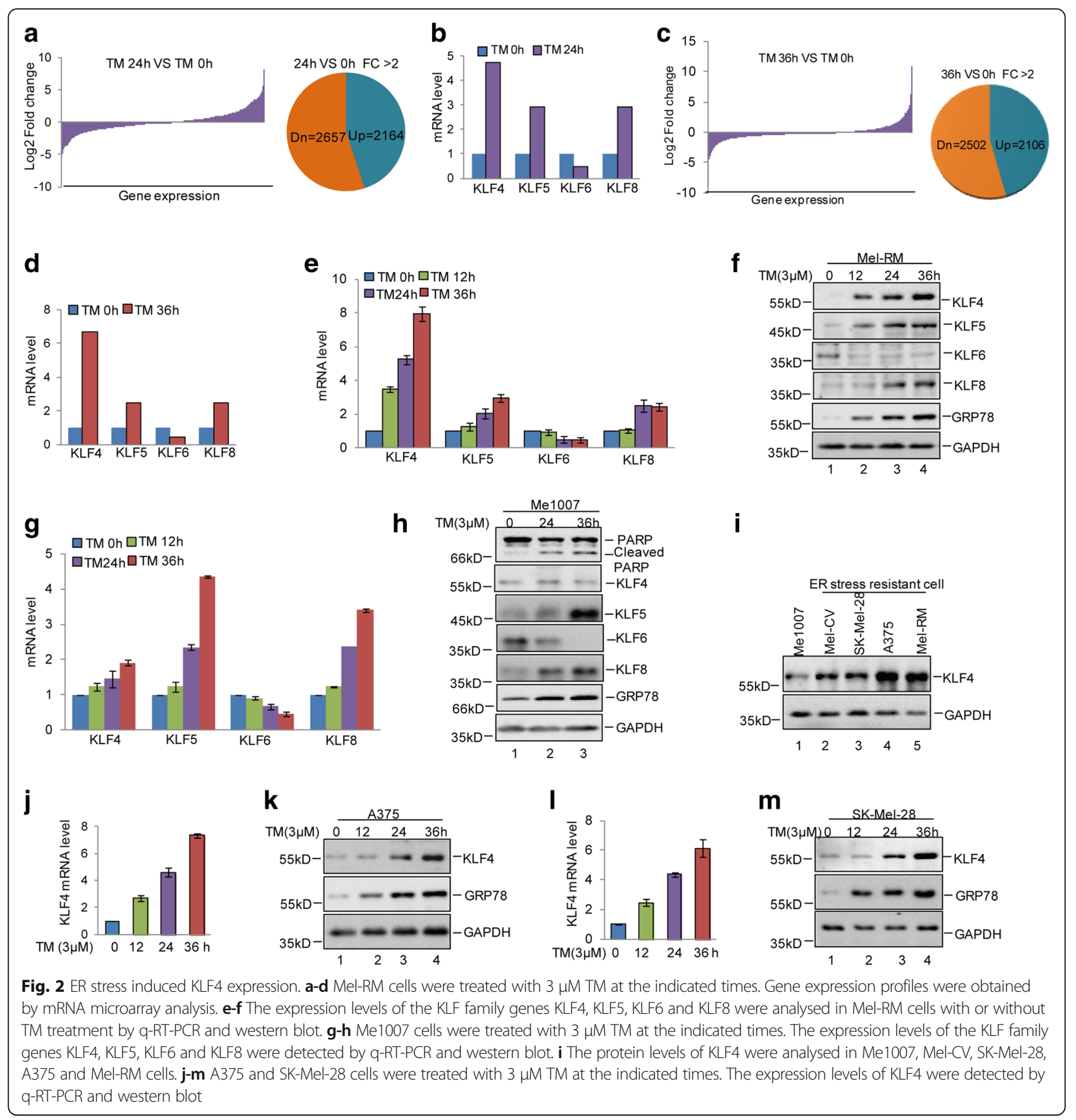

apoptosis was determined using western blot and the CCK-8 assay. As shown in Fig. 3a-d and Additional file 5: Figure S3a-b, the inhibition of KLF4 not KLF5 and KLF8 enhanced cell apoptosis and reduced cell viability. In subsequent transwell assays, the migratory capabilities of Mel-RM and A375 cells with KLF4 knockdown were apparently decreased in response to ER stress (Fig. 3e and f). To further verify this finding, we then overexpressed KLF4 in Me1007 cells. Consistent with data from the knockdown studies, Me1007 cells overexpressing KLF4 decreased cell apoptosis and enhanced cell migratory abilities under ER stress (Fig. 3g-j). Taken together, these data suggest that KLF4 plays an important role in regulating melanoma resistance to ER stress and facilitating cell metastasis.

\section{KLF4 upregulates NUCB2 expression}

To uncover the molecular mechanism underlying the regulation of ER stress resistance by KLF4, we generated KLF4 knockout (KO) Mel-RM cells using CRISPR/Cas9 technology. Gene expression profiles in KLF4 WT and 


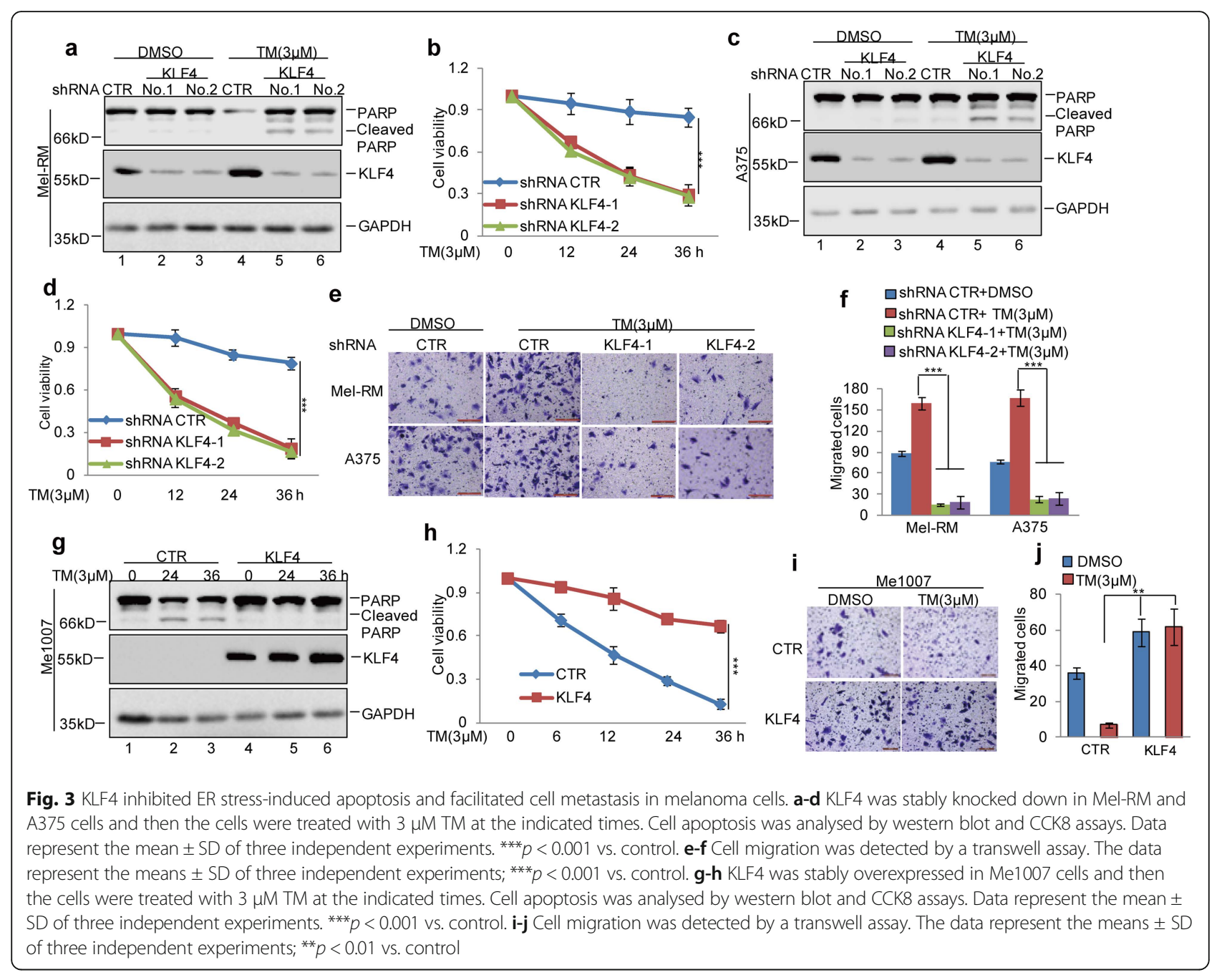

KO Mel-RM cells with or without $3 \mu \mathrm{M}$ TM treatment were obtained using RNA sequencing analysis (Fig. 4a). Among the altered genes, we found that KLF4 KO significantly suppressed NUCB2 upregulation under ER stress, and the decrease was recovered by KLF4 overexpression (Fig. 4b-e). VEGF was used as a positive control, which was indicated to be a transcriptional gene of KLF4 [28] (Additional file 6: Figure S4a). Subsequently, the expression level of NUCB2 was analysed in Me1007 cells with or without KLF4 overexpression under $3 \mu \mathrm{M}$ TM treatment. We found that NUCB2 was not induced by ER stress in Me1007 cells; however, in KLF4-overexpressing cells, the expression level of NUCB2 was increased, indicating that NUCB2 was mediated by KLF4 (Fig. 4f and g). To further confirm it, the expression level of NUCB2 was detected using q-RT-PCR and western blot in Mel-RM and A375 cells with or without KLF4 or KLF5 or KLF8 knockdown. Consistently, KLF4 not KLF5 and KLF8 knockdown suppressed the NUCB2 increase by ER stress (Fig. 4h-k and Additional file 6: Figure S4b-e). Collectively, these data validate that KLF4 upregulated NUCB2 expression in response to ER stress.

\section{KLF4 directly binds to the promoter of NUCB2}

To identify the KLF4 binding regions on the NUCB2 promoter, we first cloned the upstream sequence of NUCB2 and different truncations by PCR. Then, we inserted them into the pGL3-based luciferase reporter plasmids that were named P1-P3 (Fig. 5a). We subsequently transfected them into Mel-RM cells with or without $3 \mu \mathrm{M}$ TM treatment. As shown in Fig. 5b, the luciferase activities of P1 and P3 were increased in Mel-RM cells under ER stress treatment; however, the increase was abolished when P2 was transfected, indicating that the region $(-1000$ to $0 \mathrm{bp}$ ) was a key region for the promotion of NUCB2 under ER stress. To further verify whether the region was essential for KLF4, the truncation P3 was transfected into Mel-RM cells with or without KLF4 knockout. We found that the loss of KLF4 abolished the increase of the luciferase activity of P3 by ER stress (Fig. 5c). Similar results 


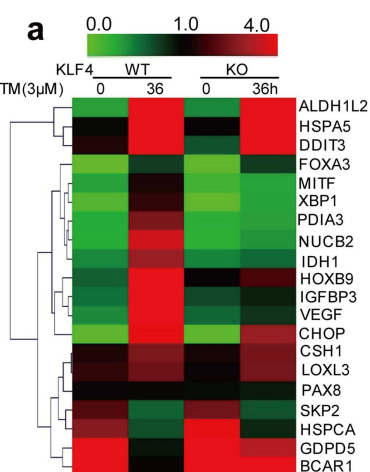

e
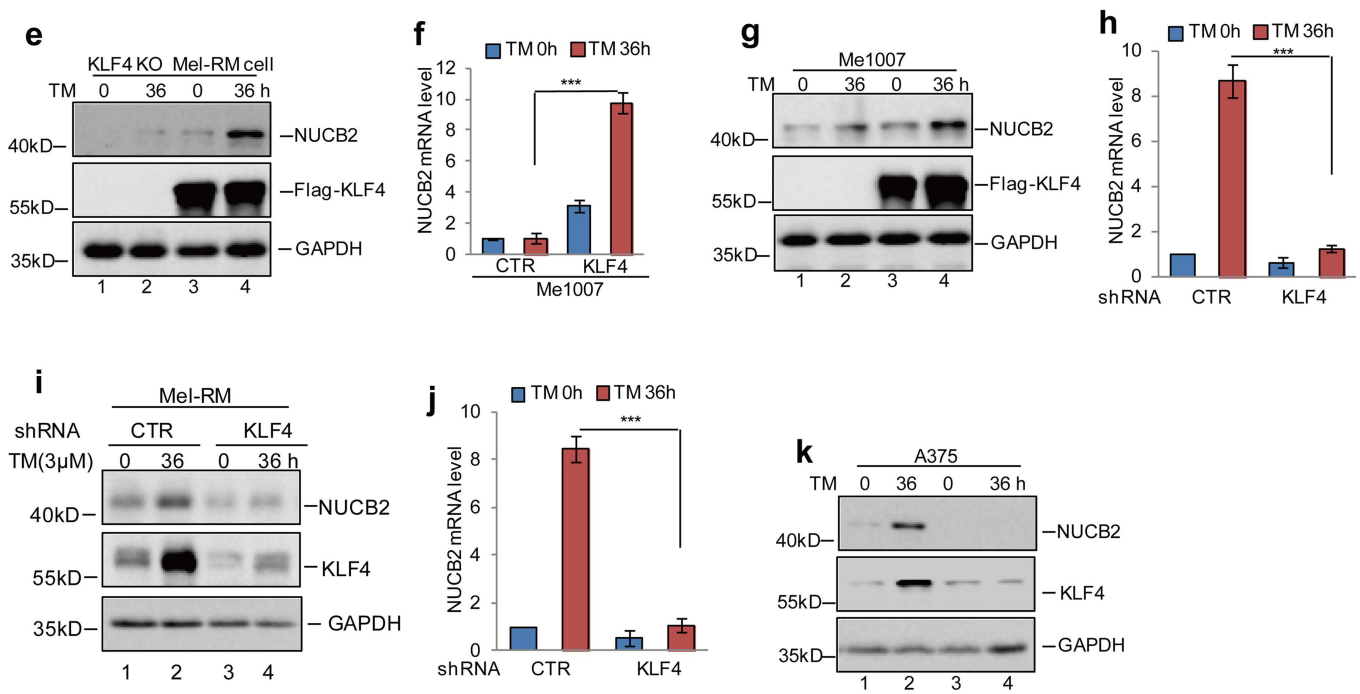

Fig. 4 KLF4 upregulated NUCB2 expression in melanoma cells. a KLF4 WT or KO Mel-RM cells were treated with $3 \mu M$ TM at the indicated times. Gene expression profiles were obtained by RNA sequencing analysis. $\mathbf{b}$ The expression levels of MITF, VEGF, PDIA3, NUCB2 and IDH1 were analysed by q-RT-PCR. The data represent the means \pm SD of three independent experiments; ${ }^{*} p<0.05,{ }^{* * *} p<0.001 \mathrm{vs}$. control. c The protein levels of KLF4 and NUCB2 were detected by western blot. $\mathbf{d}$-e Flag-KLF4 and empty vector were individually transfected into KLF4 KO Mel-RM cells and the cells were treated with $3 \mu \mathrm{M}$ TM at the indicated times. The expression levels of NUCB2 were analysed by q-RT-PCR and western blot assays. The data represent the means \pm SD of three independent experiments; ${ }^{* *} p<0.01$ vs. control. $\mathbf{f - g}$ The Me1007 cells with or without KLF4 overexpression were treated using $3 \mu \mathrm{M}$ TM at the indicated times. The expression levels of NUCB2 were analysed by q-RT-PCR and western blot assays. The data represent the means \pm SD of three independent experiments; ${ }^{* * *} p<0.001$ vs. control. h-k Mel-RM and A375 cells with or without KLF4 knockdown were treated with $3 \mu \mathrm{M}$ TM at the indicated times. The mRNA and protein levels of NUCB2 were detected by q-RT-PCR and western blot assays. Data represent the mean \pm SD of three independent experiments. ${ }^{* *} p<0.001$ vs. control

were gained in Mel-RM and A375 cells with or without KLF4 knockdown (Fig. 5d-e).

KLF4 is a zinc finger-type transcription factor that usually binds to the GC-rich element of the promoters [29]. To seek the potential KLF4 binding sites, we inspected the sequence of P3 using JASPAR software and found two putative KLF4-binding sites on the NUCB2 promoter. To verify that these potential KLF4-binding sites are indeed responsive to KLF4, a series of pGL3based luciferase reporter plasmids named BS1, BS1M, BS2 and BS2M were generated (Fig. 5f). These plasmids were individually transfected into Mel-RM cells with or without $3 \mu \mathrm{M}$ TM treatment. As shown in Fig. $5 \mathrm{~g}$ and $\mathrm{h}$, the luciferase activity of BS1, but not BS1M, BS2, and BS2M, was significantly increase in KLF4 WT Mel-RM cells under ER stress, and the increase disappeared when KLF4 was knocked out, indicating that the first binding site was a positive KLF4 binding site on the NUCB2 promoter. In addition, the subsequent chromatin immunoprecipitation (ChIP) assays showed that the chromatin fragments, corresponding to the putative KLF4-binding sites, were specifically present in anti-KLF4 immunoprecipitates from Mel-RM cells, and the bond was increased under ER stress, which was diminished by KLF4 knockout (Fig. 5i-j).

KLF4 elevates the melanoma adaptation to ER stress and metastasis by regulating NUCB2 in vitro and in vivo

To determine whether the promotion of KLF4 on the adaptation to ER stress and cell metastasis was dependent on NUCB2, we first knocked down NUCB2 


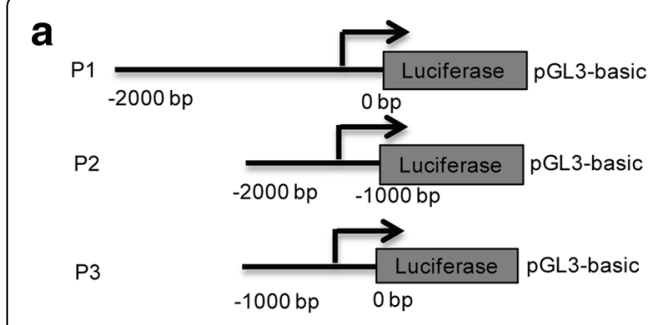

b

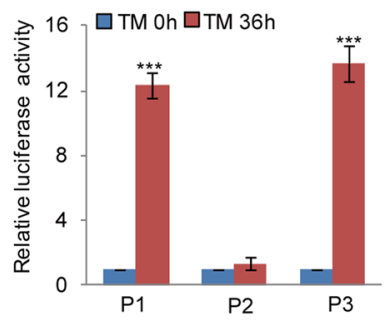

C

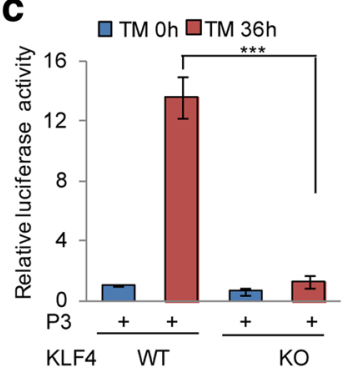

d

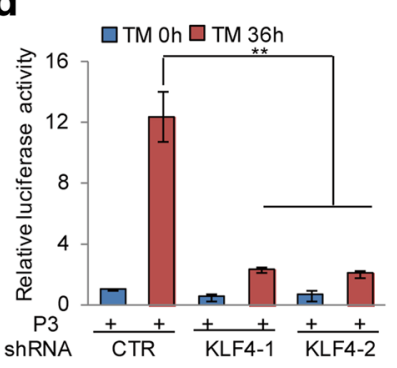

e

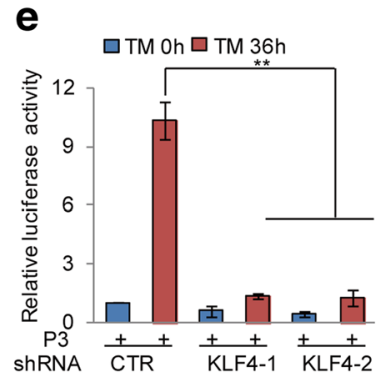

f $\mathbf{g}$

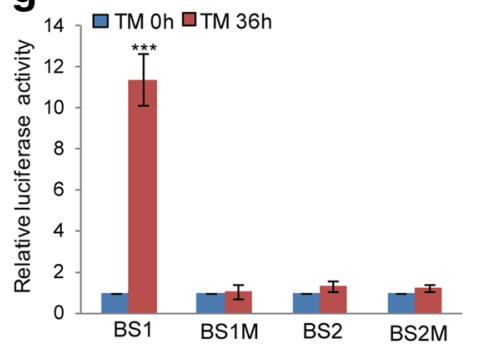

\section{h}

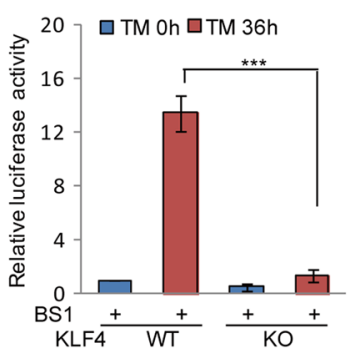

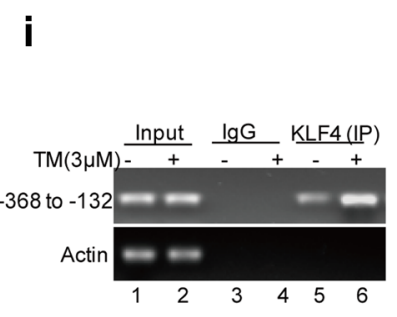

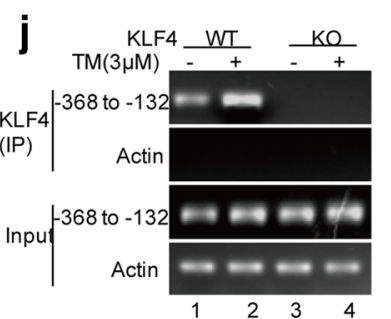

Fig. 5 KLF4 was bound to the promoter of NUCB2 in melanoma cells. a Schematic illustration of pGL3-based reported constructs were used in luciferase assays to examine the transcriptional activity of NUCB2. $\mathbf{b}$ The promoters of NUCB2 named P1, P2 and P3 were individually transfected into Mel-RM cells with or without TM treatment. The luciferase activity was measured. The data represent the means \pm SD of three independent experiments; ${ }^{* *} p<0.001$ vs. control. c P3 was transfected into Mel-RM cells with or without KLF4 knockout. The cells were treated with $3 \mu \mathrm{M}$ TM. The luciferase activity of NUCB2 promoter was measured by the luciferase reporter assay. The data represent the means \pm SD of three independent experiments; ${ }^{* * *} p<0.001$ vs. control. d-e P3 was transfected into Mel-RM and A375 cells with or without KLF4 knockdown. The cells were treated with $3 \mu \mathrm{M}$ TM. The luciferase activity of NUCB2 promoter was measured by the luciferase reporter assay. The data represent the means \pm SD of three independent experiments; ${ }^{* *} p<0.01$ vs. control. $\mathbf{f}$ The potential KLF4-binding sites were inspected by JASPAR. A schematic illustration of KLF4 wild type binding site 1 (BS1), binding site 2 (BS2) and the matching mutant BS1M, BS2M that were used in the luciferase assays is shown. $\mathbf{g}$ BS1, BS1M, BS2 and BS2M were individually transfected into Mel-RM cells with or without $3 \mu M$ TM treatment. The luciferase activity was measured by the luciferase reporter assay. The data represent the means \pm SD of three independent experiments; ${ }^{* *} p<0.001 \mathrm{vs}$. control. $\mathbf{h}$ BS1 was transfected into Mel-RM with or without KLF4 knockout. The cells were treatment with $3 \mu \mathrm{M}$ TM. The luciferase activity was measured by the luciferase reporter assay. The data represent the means \pm SD of three independent experiments; ${ }^{* * *} p<0.001$ vs. control. i-j ChIP analysis showed the binding of KLF4 to the promoter of NUCB2 in KLF4 WT or KO Mel-RM cells in response to $3 \mu \mathrm{M}$ TM treatment. An isotype-matched lgG was used as a negative control

in Mel-RM cells, and then the cells were treated with $3 \mu \mathrm{M}$ TM. Compared with the control cells, deficiency in NUCB2 promoted ER stress-induced apoptosis and decreased cell migration, which was consistent with the role of KLF4 in melanoma cells (Fig. 6a-b). Whereafter, we overexpressed NUCB2 into KLF4 KO Mel-RM cells and found that the effects of KLF4 depletion on melanoma adaptation to ER stress and metastasis were reversed by NUCB2 overexpression (Fig. 6e-g).
To further identify the effects of KLF4 on the adaptation to ER stress and cell metastasis by regulating NUCB2 in vivo, NUCB2 was overexpressed into KLF4 KO Mel-RM cells, and the expression levels of KLF4 and NUCB2 were detected using western blot (Additional file 7: Figure S5). First, the cells were subcutaneously injected into nude mice. Compared with control cells, the loss of KLF4 decreased tumour growth and increased cell apoptosis; however, the phenotypes were reversed by NUCB2 overexpression (Fig. 6h-l). The cells were then injected 


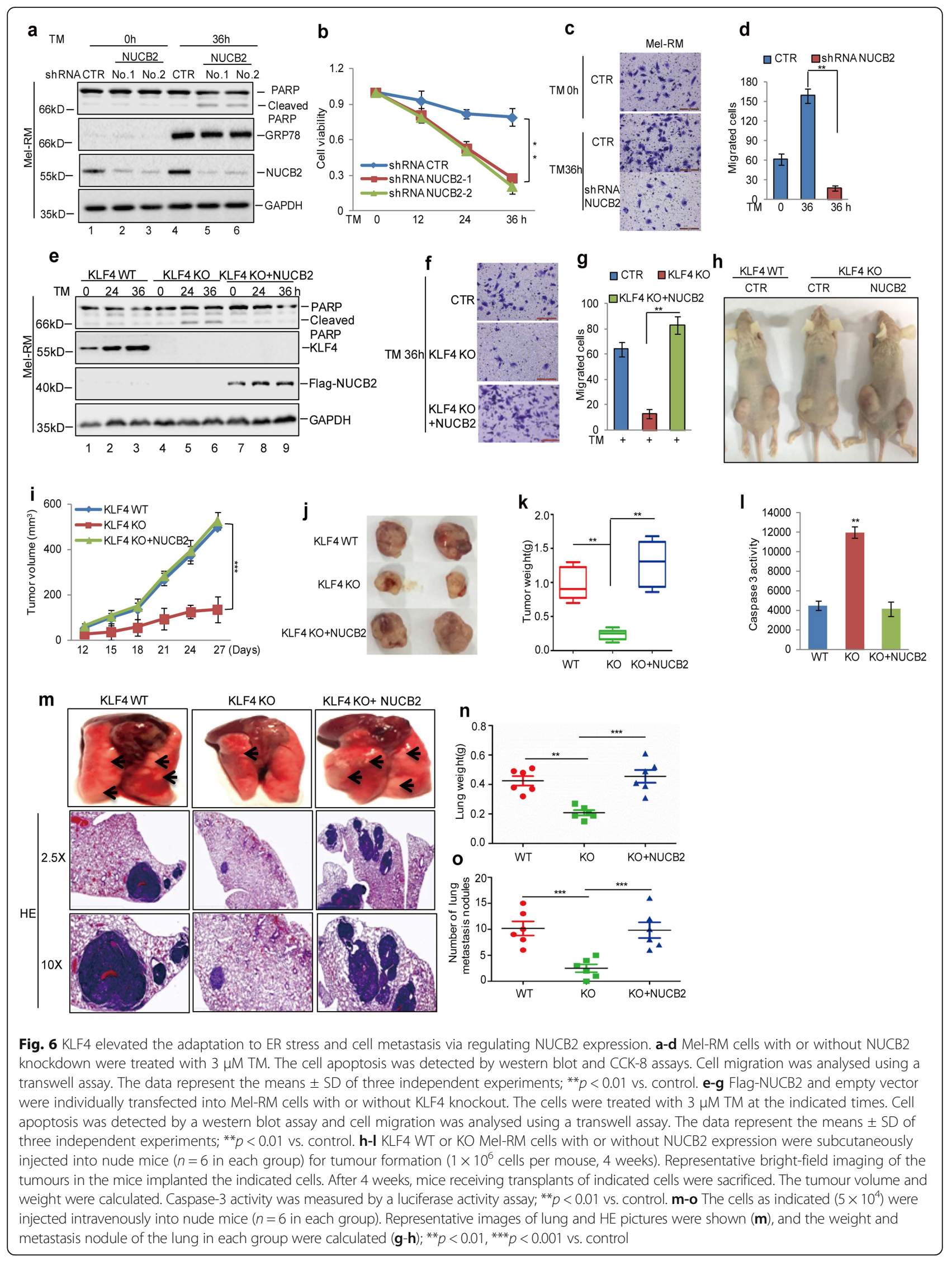


intravenously into the nude mice, and the migratory abilities of these cells were assessed in vivo. As shown in Fig. 6m-o, the deficiency of KLF4 decreased lung metastatic abilities of melanoma cells, which was reversed by NUCB2 overexpression. Taken together, these data indicate that the effects of KLF4 on melanoma adaptation to ER stress and metastasis were dependent on NUCB2.

The expression of KLF4 is increased in melanoma tissues and is associated with NUCB2 expression

To further confirm the biological importance of the KLF4-NUCB2 axis in melanoma, the protein levels of KLF4 and NUCB2 in melanoma tissues and normal tissues were analysed using immunohistochemical staining (Fig. 7a). We found that the relative expression levels of KLF4 and NUCB2 were significantly increased in melanoma tissues, and the protein level of KLF4 was positively correlated with NUCB2 in melanoma tissues (Fig. 7b-d).

\section{Discussion}

In this study, we investigated the role of ER stress in melanoma cell metastasis and found that adaptation to ER stress favoured cell metastasis, otherwise, decreasing cell metastasis. Further mechanistic studies indicated that KLF4 induced by ER stress inhibited ER stress-induced apoptosis and promoted cell metastasis by transcriptionally upregulating NUCB2 expression in vivo and in vitro. Thus, our data indicated a mechanism in which adaptation to ER stress plays a key role in accelerating melanoma cell metastasis.

ER stress is an important biologic process that is usually induced by physiological and pathological conditions such as nutrient deprivation, hypoxia, $\mathrm{ER} \mathrm{Ca}^{2+}$ depletion, impaired glycosylation or disulfide bond formation, oxidative stress and viral or bacterial infection [16]. Adaptation to ER stress has been indicated to play an essential role in melanoma, which not only renders them resistant to various therapeutic agents but also favours the escape of melanoma cells from anti-tumour immunity [30-33]. Similarly, our data indicated that melanoma adaptation to ER stress was an important cause for promoting cell metastasis. We also found that KLF4 induced by ER stress promoted melanoma adaptation to ER stress and cell metastasis.

KLF4 is a zinc finger-type transcription factor that modulates diverse and essential functions in multiple

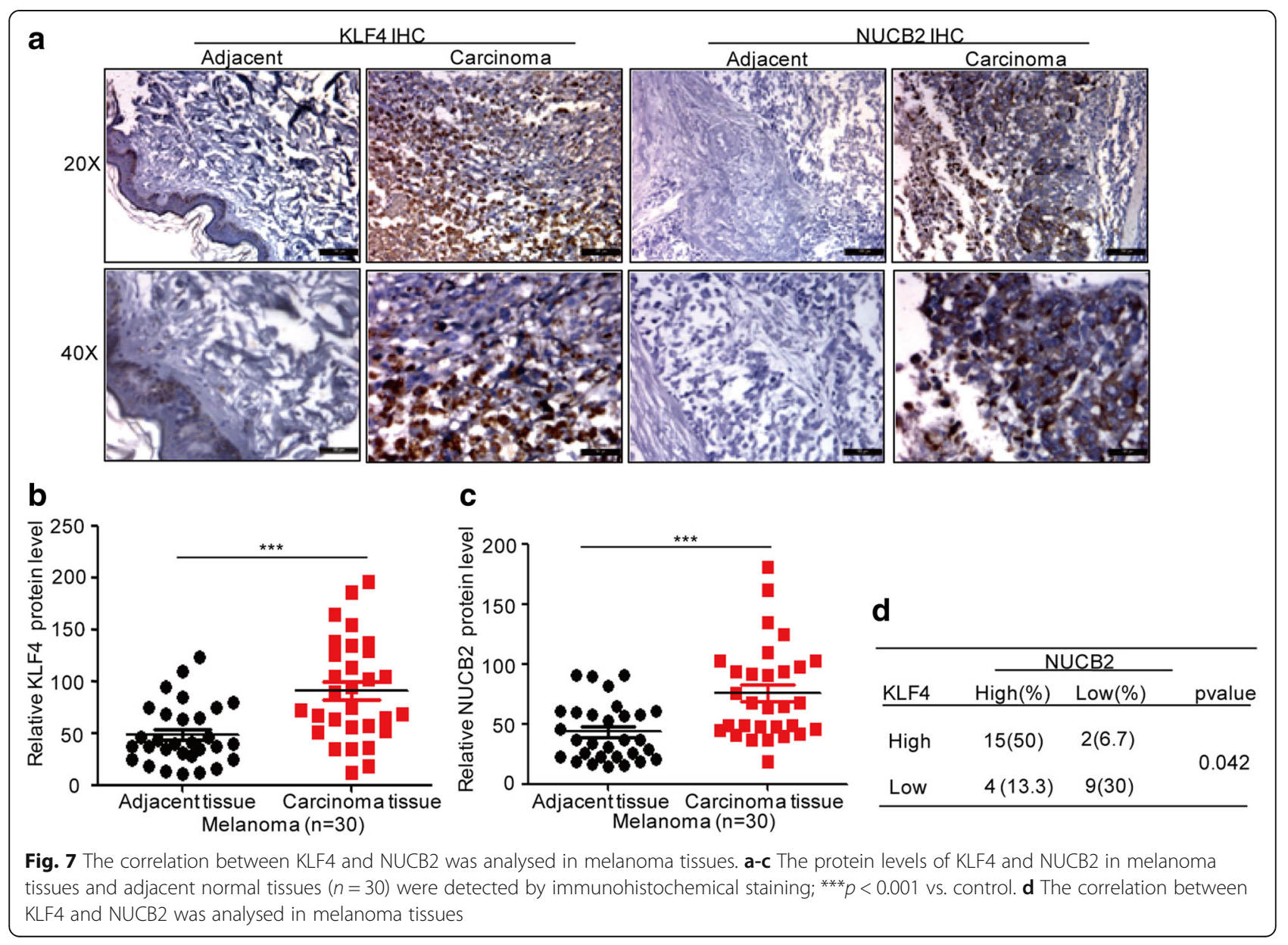


cellular processes, including proliferation, differentiation, migration, inflammation and pluripotency [34, 35]. In tumours, KLF4 acts as an oncogene or a tumour suppressor depending on the types of cancers [36-38]. Recent studies indicated that KLF4 was increased in melanoma and enhanced tumour growth [39]. Consistently, our findings provided a series of evidence supporting the oncogenic role of KLF4 in melanoma adaptation to ER stress. First, KLF4 ablation dramatically reduced melanoma adaption to ER stress and inhibited cell metastasis in vitro and in vivo. Second, exogenous expression of KLF4 in ER stress non-resistant cells suppressed cell apoptosis and promoted cell metastasis. Third, the expression levels of KLF4 were increased in melanoma tissues and KLF4 was induced by ER stress in a transcriptional manner. Although KLF4 is modulated by a variety of environmental signals, including DNA damage, inflammation and oxidative stress, the molecular mechanism of the KLF4 increase under ER stress is still unknown. Recent study indicated that E2F1 was a potential transcription factor in melanoma. However, we need further study to investigate whether E2F1 involved in the KLF4 increase under ER stress.

KLF4 can both activate and repress transcription, depending on the contents of target promoters and its interacting partners $[29,35]$. To seek the targeted genes of KLF4 under ER stress, the gene expression profiles in KLF4 WT and KO Mel-RM cells with or without TM treatment were obtained by RNA sequencing analysis. Among the altered genes, we found that KLF4 KO decreased NUCB2 expression in response to ER stress.

NUCB2, a neuropeptide, is a metablic factor that plays an important role in food intake and energy homeostasis [40]. An increasing number of studies indicated that NUCB2 acts as a tumour promoter enhancing tumourigenesis and metastasis in breast cancer and renal cell carcinoma (RCC) [41-44]. In our study, we uncovered the oncogene role of NUCB2 in melanoma and found that NUCB2 was induced by ER stress for the first time. Furthermore, our data also showed that elevated NUCB2 plays an important role in inhibiting ER stress-induced apoptosis and promoting cell metastasis in melanoma, and the expression level of NUCB2 was increased in melanoma tissues. Although the role of NUCB2 was indicated in our study, the downstream pathway of NUCB2 in melanoma will be explored in the future. In brief, our data showed that adaptation to ER stress is essential for promoting melanoma metastasis and provided strong evidence that the KLF4-NUCB2 pathway contributes to melanoma metastasis under ER stress by elevating melanoma ER stress resistance.

\section{Conclusions}

In summary, our study indicates that KLF4 was an important regulator in melanoma adaptation to ER stress and cell metastasis. We found that KLF4 induced by ER stress could directly bind to the promoter of NUCB2 and promote NUCB2 expression, leading to the increase in melanoma ER stress resistance and cell metastasis. Thus, our data revealed that the KLF4-NUCB2 pathway plays an important role in melanoma ER stress resistance and cell metastasis, and KLF4 may be a promising specific target for melanoma therapy.

\section{Additional files}

\begin{abstract}
Additional file 1: Table S2. Clinical information of Patients with melanoma. (XLSX $11 \mathrm{~kb}$ )

Additional file 2: Figure S1. Me1007, Mel-CV, SK-Mel-28, A375 and Mel-RM cells were treated with $3 \mu \mathrm{M}$ TM. Cell viability was measured by the CCK- 8 assay. The data represent the means \pm SD of three independent experiments. ${ }^{* *} p<0.001$ vs. control. (TIF 52 kb)
\end{abstract}

Additional file 3: Table S1. Differentially expressed genes. (XLS $4331 \mathrm{~kb}$ ) Additional file 4: Figure S2. (a-b) Mel-RM and A375 cells were treated with $1 \mu \mathrm{M}$ TG for the indicated times. The expression levels of KLF4 were detected using western blot and $\mathrm{q}-\mathrm{RT}$ T-PCR. The data represent the means \pm SD of three independent experiments. (TIF $196 \mathrm{~kb}$ )

Additional file 5: Figure S3. (a-b) Mel-RM with or without KLF5 or KLF8 knockdown were treated with $3 \mu \mathrm{M}$ TM. Cell lysates were then subjected to western blot analysis using the indicated antibodies. (TIF $192 \mathrm{~kb}$ )

Additional file 6: Figure S4. (a) the MRNA levels of VEGF were analysed by q-RT-PCR in KLF4 WT, KLF4 KO or KLF4 KO + Flag-KLF4 Mel-RM cells with or without $3 \mu \mathrm{M}$ TM treatment for the indicated times. The data represent the means \pm SD of three independent experiments. ${ }^{* *} p<0.01$, ${ }^{* * *} p<0.001$ vs. control. (b-e) The expression levels of NUCB2 were detected by western blot and q-RT-PCR assays in Mel-RM cells with or without KLF5 or KLF8 knockdown under TM treatment. The data represent the means \pm SD of three independent experiments. ${ }^{* *} p<0.001$ vs. control. (TIF 252 kb)

Additional file 7: Figure S5. NUCB2 was transfected in a stable manner into Mel-RM cells with or without KLF4 knockout. Cell lysates were then subjected to western blot analysis using the indicated antibodies. (TIF $69 \mathrm{~kb}$ )

\section{Abbreviations}

CCK-8: Cell Counting Kit-8; ChIP: Chromatin immunoprecipitation; CTLA4: Cytotoxic T-lymphocyte-associated protein 4; ER stress: Endoplasmic reticulum stress; HOXB9: Homeobox protein Hox-B9; KLF4: Kruppel-like factor 4; KO: Knockout; MEK: Mitogen-activated protein extracellular kinase; NUCB2: Nucleobindin 2; PD1: Programmed cell death protein 1; q-RTPCR: Quantitative real-time polymerase chain reaction assay; RCC: Renal cell carcinoma; RIPK1: Receptor-interacting serine/threonine-protein kinase 1; TM: Tunicamycin; TMA: Human tissue microarray analysis

\section{Acknowledgements}

We kindly thank the National Nature Science Foundation of China for the funding.

\section{Funding}

This research was supported by the National Nature Science Foundation of China (No. 81502368 to Lei Jin; 81402260 to Chuanchun Han; 81670383 to Dongmei Zhang) and the Liaoning Provincial Natural Science Foundation of China (No. 2015020309 to Chuanchun Han).

\section{Authors' contributions}

CCH and WZZ designed the whole experiments; DMZ, JRL, YLC, BBM and LZ conducted molecular biology experiments and wrote the manuscript; LJ, NL, and RPH conducted the pharmacological studies and performed the statistical analyses. All authors read and approved the final manuscript. 


\section{Ethics approval and consent to participate}

For animal experiments, all animal procedures were performed in accordance with the institutional guidelines for the care and use of laboratory animals approved by the Animal Care and Use Committee of Dalian Medical University and the National Institutes of Health guide for the care and use of laboratory animals. The tissue microarray was commercially purchased from Alenabio (Xi'an, China). The characteristics of the patients and their tumours were collected through the review of medical records and pathologic reports. Informed consent with approval of the ethics committee of Taizhou Hospital of Zhejiang Province was obtained. All of the methods in this study were in accordance with the approved guidelines, and all of the experimental protocols were approved by the ethics committee of Taizhou Hospital of Zhejiang Province.

\section{Consent for publication}

All the authors of this review give their consent for publication.

\section{Competing interests}

The authors declare that they have no competing interests.

\section{Publisher's Note}

Springer Nature remains neutral with regard to jurisdictional claims in published maps and institutional affiliations.

\section{Author details}

'Institute of Cancer Stem Cell, Dalian Medical University, Dalian 116044, China. ${ }^{2}$ Department of Orthopedics, Second Affiliated Hospital, Dalian Medical University, Dalian 116044, China. ${ }^{3}$ Department of Physiology, College of Basic Medical Sciences, Dalian Medical University, Dalian 116044, China. ${ }^{4}$ Department of Dermatology, the First Affiliated Hospital, Dalian Medical University, Liaoning 116027, China.

\section{Received: 17 April 2018 Accepted: 13 July 2018}

\section{Published online: 28 July 2018}

\section{References}

1. Houghton AN, Polsky D. Focus on melanoma. Cancer Cell. 2002;2:275-8.

2. Schagdarsurengin U, Lammert A, Schunk N, Sheridan D, Gattenloehner S, Steger K, Wagenlehner F, Dansranjavin T. Impairment of IGF2 gene expression in prostate cancer is triggered by epigenetic dysregulation of IGF2-DMRO and its interaction with KLF4. Cell Commun Signal. 2017;15:40.

3. Silvestris N, Ciliberto G, De Paoli P, Apolone G, Lavitrano ML, Pierotti MA Stanta G. On the behalf of the dynamic medicine Og. Liquid dynamic medicine and $\mathrm{N}$-of-1 clinical trials: a change of perspective in oncology research. J Exp Clin Cancer Res. 2017;36:128.

4. Singh SJ, Turner W, Glaser DE, McCloskey KE, Filipp FV. Metabolic shift in density-dependent stem cell differentiation. Cell Commun. Signal. 2017;15:44.

5. Andtbacka RH, Kaufman HL, Collichio F, Amatruda T, Senzer N, Chesney J, Delman KA, Spitler LE, Puzanov I, Agarwala SS, Milhem M, Cranmer L, et al. Talimogene Laherparepvec improves durable response rate in patients with advanced melanoma. J Clin Oncol Off J Am Soc Clin Oncol. 2015;33:2780-8.

6. Luke JJ, Flaherty KT, Ribas A, Long GV. Targeted agents and immunotherapies: optimizing outcomes in melanoma. Nat Rev Clin Oncol. 2017;14:463-82

7. Weber JS, D'Angelo SP, Minor D, Hodi FS, Gutzmer R, Neyns B, Hoeller C, Khushalani NI, Miller WH Jr, Lao CD, Linette GP, Thomas L, et al. Nivolumab versus chemotherapy in patients with advanced melanoma who progressed after anti-CTLA-4 treatment (CheckMate 037): a randomised, controlled, open-label, phase 3 trial. Lancet Oncol. 2015;16:375-84.

8. Granier C, De Guillebon E, Blanc C, Roussel H, Badoual C, Colin E, Saldmann A, Gey A, Oudard S, Tartour E. Mechanisms of action and rationale for the use of checkpoint inhibitors in cancer. ESMO open. 2017;2:e000213.

9. Hermel DJ, Ott PA. Combining forces: the promise and peril of synergistic immune checkpoint blockade and targeted therapy in metastatic melanoma. Cancer Metastasis Rev. 2017;36:43-50.

10. Manson G, Norwood J, Marabelle A, Kohrt H, Houot R. Biomarkers associated with checkpoint inhibitors. Ann Oncol. 2016;27:1199-206.

11. Park JJ, Diefenbach RJ, Joshua AM, Kefford RF, Carlino MS, Rizos H. Oncogenic signaling in uveal melanoma. Pigment Cell Melanoma Res. 2018;8:12701-8.
12. Rotte A, Bhandaru M, Zhou Y, McElwee KJ. Immunotherapy of melanoma: present options and future promises. Cancer Metastasis Rev. 2015;34:115-28.

13. Wahid M, Jawed A, Mandal RK, Dar SA, Akhter N, Somvanshi P, Khan F, Lohani M, Areeshi MY, Haque S. Recent developments and obstacles in the treatment of melanoma with BRAF and MEK inhibitors. Crit Rev Oncol Hematol. 2018;125:84-8.

14. Warner AB, Postow MA. Combination controversies: checkpoint inhibition alone or in combination for the treatment of melanoma? Oncology. 2018; 32:228-34.

15. Nguyen DX, Bos PD, Massague J. Metastasis: from dissemination to organspecific colonization. Nat Rev Cancer. 2009;9:274-84.

16. Rutkowski DT, Kaufman RJ. A trip to the ER: coping with stress. Trends Cell Biol. 2004;14:20-8.

17. Jiang CC, Lucas K, Avery-Kiejda KA, Wade M, deBock CE, Thorne RF, Allen J, Hersey $\mathrm{P}$, Zhang XD. Up-regulation of Mcl-1 is critical for survival of human melanoma cells upon endoplasmic reticulum stress. Cancer Res. 2008;68:6708-17.

18. Jin L, Hu WL, Jiang CC, Wang JX, Han CC, Chu P, Zhang L, Thorne RF, Wilmott J, Scolyer RA, Hersey P, Zhang XD, et al. MicroRNA-149*, a p53responsive microRNA, functions as an oncogenic regulator in human melanoma. Proc Natl Acad Sci U S A. 2011;108:15840-5.

19. Luan Q, Jin L, Jiang CC, Tay KH, Lai F, Liu XY, Liu YL, Guo ST, Li CY, Yan XG, Tseng HY, Zhang XD. RIPK1 regulates survival of human melanoma cells upon endoplasmic reticulum stress through autophagy. Autophagy. 2015; 11:975-94.

20. Lin J, Zhang D, Fan Y, Chao Y, Chang J, Li N, Han L, Han C. Regulation of Cancer stem cell self-renewal by HOXB9 antagonizes endoplasmic reticulum stress-induced melanoma cell apoptosis via the miR-765-FOXA2 Axis. J Investig Dermatol. 2018;8(6):1019-29.

21. Wang JY, Liu GZ, Wilmott JS, La T, Feng YC, Yari H, Yan XG, Thorne RF, Scolyer RA, Zhang XD, Jin L. Skp2-mediated stabilization of MTH1 promotes survival of melanoma cells upon oxidative stress. Cancer Res. 2017;77:6226-39.

22. Jiang CC, Chen LH, Gillespie S, Wang YF, Kiejda KA, Zhang XD, Hersey P. Inhibition of MEK sensitizes human melanoma cells to endoplasmic reticulum stress-induced apoptosis. Cancer Res. 2007;67:9750-61.

23. Biagioni A, Chilla A, Andreucci E, Laurenzana A, Margheri F, Peppicelli S, Del Rosso M, Fibbi G. Type II CRISPR/Cas9 approach in the oncological therapy. J Exp Clin Cancer Res. 2017;36:80.

24. Li X, Ma C, Zhang L, Li N, Zhang X, He J, He R, Shao M, Wang J, Kang L, Han C. LnCRNAAC132217.4, a KLF8-regulated long non-coding RNA, facilitates oral squamous cell carcinoma metastasis by upregulating IGF2 expression. Cancer Lett. 2017;407:45-56.

25. Zhang L, Wang Y, Li X, Xia X, Li N, He R, He H, Han C, Zhao W. ZBTB7A enhances osteosarcoma Chemoresistance by transcriptionally repressing IncRNALINC00473-IL24 activity. Neoplasia. 2017;19:908-18.

26. Ma B, Yuan Z, Zhang L, Lv P, Yang T, Gao J, Pan N, Wu Q, Lou J, Han C, Zhang B. Long non-coding RNA AC023115.3 suppresses chemoresistance of glioblastoma by reducing autophagy. Biochim Biophys Acta. 2017;1864: 1393-404.

27. Yang X, Du T, Wang X, Zhang Y, Hu W, Du X, Miao L, Han C. IDH1, a CHOP and C/EBPbeta-responsive gene under ER stress, sensitizes human melanoma cells to hypoxia-induced apoptosis. Cancer Lett. 2015;365:201-10.

28. Wang Y, Yang C, Gu Q, Sims M, Gu W, Pfeffer LM, Yue J. KLF4 promotes angiogenesis by activating VEGF signaling in human retinal microvascular endothelial cells. PLoS One. 2015;10:e0130341.

29. Zhang W, Geiman DE, Shields JM, Dang DT, Mahatan CS, Kaestner KH, Biggs $J R$, Kraft AS, Yang WW. The gut-enriched Kruppel-like factor (Kruppel-like factor 4) mediates the transactivating effect of p53 on the p21WAF1/Cip1 promoter. J Biol Chem. 2000;275:18391-8.

30. Han C, Jin L, Mei Y, Wu M. Endoplasmic reticulum stress inhibits cell cycle progression via induction of p27 in melanoma cells. Cell Signal. 2013;25:144-9.

31. Hersey P, Zhang XD. Adaptation to ER stress as a driver of malignancy and resistance to therapy in human melanoma. Pigment Cell Melanoma Res. 2008;21:358-67.

32. La Porta CA. Mechanism of drug sensitivity and resistance in melanoma. Curr Cancer Drug Targets. 2009;9:391-7.

33. Bettigole SE, Glimcher LH. Endoplasmic reticulum stress in immunity. Annu Rev Immunol. 2015;33:107-38.

34. Evans PM, Liu C. Roles of Krupel-like factor 4 in normal homeostasis, cancer and stem cells. Acta Biochim Biophys Sin. 2008;40:554-64.

35. Yoshida T, Gan Q, Owens GK. Kruppel-like factor 4, Elk-1, and histone deacetylases cooperatively suppress smooth muscle cell differentiation 
markers in response to oxidized phospholipids. Am J Physiol Cell Physiol. 2008;295:C1175-82.

36. Tetreault MP, Yang Y, Katz JP. Kruppel-like factors in cancer. Nat Rev Cancer. 2013:13:701-13.

37. Zhang Y, Liang W, Zhang P, Chen J, Qian H, Zhang X, Xu W. Circular RNAs: emerging cancer biomarkers and targets. J Exp Clin Cancer Res. 2017;36:152.

38. Zhou P, Qin J, Li Y, Li G, Wang Y, Zhang N, Chen P, Li C. Combination therapy of PKCzeta and COX-2 inhibitors synergistically suppress melanoma metastasis. J Exp Clin Cancer Res. 2017;36:115.

39. Riverso M, Montagnani V, Stecca B. KLF4 is regulated by RAS/RAF/MEK/ERK signaling through E2F1 and promotes melanoma cell growth. Oncogene. 2017;36:3322-33.

40. Oh IS, Shimizu H, Satoh T, Okada S, Adachi S, Inoue K, Eguchi H, Yamamoto M, Imaki T, Hashimoto K, Tsuchiya T, Monden T, et al. Identification of nesfatin-1 as a satiety molecule in the hypothalamus. Nature. 2006:443:709-12.

41. Suzuki S, Takagi K, Miki Y, Onodera Y, Akahira J, Ebata A, Ishida T, Watanabe $\mathrm{M}$, Sasano H, Suzuki T. Nucleobindin 2 in human breast carcinoma as a potent prognostic factor. Cancer Sci. 2012;103:136-43.

42. Xu H, Li W, Qi K, Zhou J, Gu M, Wang Z. A novel function of NUCB2 in promoting the development and invasion of renal cell carcinoma. Oncol Lett. 2018;15:2425-30.

43. Garufi A, Pistritto G, Baldari S, Toietta G, Cirone M, D'Orazi G. p53-dependent PUMA to DRAM antagonistic interplay as a key molecular switch in cell-fate decision in normal/high glucose conditions. J Exp Clin Cancer Res. 2017;36:126.

44. Huang X, Xie X, Wang H, Xiao X, Yang L, Tian Z, Guo X, Zhang L, Tang H, Xie X. PDL1 And LDHA act as ceRNAs in triple negative breast cancer by regulating miR-34a. J Exp Clin Cancer Res. 2017;36:129.

Ready to submit your research? Choose BMC and benefit from:

- fast, convenient online submission

- thorough peer review by experienced researchers in your field

- rapid publication on acceptance

- support for research data, including large and complex data types

- gold Open Access which fosters wider collaboration and increased citations

- maximum visibility for your research: over $100 \mathrm{M}$ website views per year

At $\mathrm{BMC}$, research is always in progress.

Learn more biomedcentral.com/submissions 